\title{
Are there knowledge and attitude deficits on leprosy? A study among medical interns and final year medical students in southeast Nigeria
}

\author{
NGOZI EKEKE ${ }^{\mathrm{a}}$, JOSEPH N. CHUKW U', \\ CHARLES C. NWAFOR ${ }^{\mathrm{a}}$, ANTHONY O. MEKA ${ }^{\mathrm{a}}$, \\ EMMANUEL AGUWA ${ }^{\mathrm{b}}, \mathrm{KENECHI} \mathrm{UWAKWE}^{\mathrm{c}}$, \\ UCHE ANYANWAGU ${ }^{\mathrm{d}}$, IJEOMA NDUKA ${ }^{\mathrm{e}}$, \\ BEN AZUOGU ${ }^{\mathrm{f}}$, DANIEL OSHI ${ }^{\mathrm{g}}$ \& EDMUND N. OSSAI \\ ${ }^{\mathrm{a}}$ German Leprosy and TB Relief Association, Nigeria \\ ${ }^{\mathrm{b}}$ College of Medicine and Health Sciences, University of Nigeria, Nsukka, \\ Nigeria \\ ${ }^{\mathrm{c}}$ College of Medicine and Health Sciences, Imo State University, Nigeria \\ ${ }^{\mathrm{d}}$ School of Medicine, University of Nottingham, UK \\ ${ }^{\mathrm{e}}$ College of Medicine and Health Sciences, Abia State University, Nigeria \\ ${ }^{\mathrm{f}}$ College of Medicine and Health Sciences, Ebonyi State University, Nigeria \\ ${ }^{\mathrm{g}}$ Department of Community Health and Psychiatry, University of West \\ Indies, Kingston, Jamaica
}

Accepted for publication 29 October 2019

\begin{abstract}
Summary
Background: Lack of knowledge about leprosy exists even among medical practitioners around the world. This study was designed to assess the knowledge, attitude and treatment practice regarding leprosy among final year medical students and medical interns in southeast Nigeria.

Methods: This was a comparative cross sectional study. All final year medical students and all medical interns in five tertiary health institutions in southeast Nigeria were included in the study. Information was obtained using pre-tested, self-administered, semi-structured questionnaires. Chi square test and multivariate analysis using binary logistic regression were used in the analysis. Significance was determined to be $p$ $<0.05$.

Results: Of the 1045 respondents (interns 477 , response rate: $81.1 \%$ and medical students 568 , response rate: $97.2 \%$ ), only $29.0 \%$ of medical interns and $24.7 \%$ of medical students had a good knowledge of leprosy. A positive attitude towards leprosy care was found in $49.9 \%$ and $38.4 \%$ of medical interns and students respectively. Clinical demonstration workshops on leprosy were attended by $24.5 \%$ and $25.7 \%$ of medical interns and students, respectively. Predictors of a good knowledge of leprosy included having attended a clinical demonstration on leprosy, $(\mathrm{AOR}=2.9 ; 95 \% \mathrm{CI}$ : 2.1-3.9). Predictors of a positive attitude included male gender, $(\mathrm{AOR}=1.8 ; 95 \%$
\end{abstract}


CI: 1.4-2.3) and having a good knowledge of leprosy, (AOR = 1.6; 95\% CI: 1.2-2.2). Predictors of good treatment practice included having attended a clinical demonstration on leprosy, (AOR $=2.1 ; 95 \% \mathrm{CI}: 1.5-2.9)$ and having a good knowledge of leprosy, (AOR $=2.0 ; 95 \%$ CI: $1.4-2.7$ ).

Conclusions: The study highlighted huge knowledge and attitude deficits regarding leprosy among young medical professionals in southeast Nigeria. Emphasis should be on improving practical knowledge of leprosy through clinical demonstrations, to avoid a dearth of leprosy expertise in future generations.

Keywords: Knowledge, attitude, practice, leprosy, clinical demonstration, medical interns, medical students, southeast Nigeria

\section{Introduction}

In Nigeria, neglected tropical diseases including leprosy are among the forty communicable and non-communicable diseases and conditions included in Integrated Disease Surveillance and Response. ${ }^{1}$ Even though Nigeria attained the WHO leprosy elimination target of 1 case per 10, 000 population at national level in $1998,{ }^{2}$ the country is still regarded as one of the leprosy endemic countries in the world. ${ }^{1}$ At sub-national level, a number of states and local government areas (districts) across the country are yet to achieve the WHO elimination target. Furthermore, at national level, the proportion of newly diagnosed cases with WHO Grade 2 disability has increased from $12 \%$ in 2005 to $28 \%$ in 2018 , implying late presentation of cases, while the proportion of children among new cases was as high as $9.4 \%$ in 2005 but reported to be $4 \%$ in 2018 . These figures may suggest a trend towards under-detection of leprosy in children, and late detection in adults. The corresponding figures for WHO Grade 2 disability rate and child proportion among new leprosy cases notified in 2018 in southeast Nigeria were $31 \%$ and $2 \%$ respectively. ${ }^{1,3}$ Although leprosy remains a public health problem in Nigeria, it has been shown that the country is faced with loss of expertise in the clinical management of leprosy. ${ }^{4}$

Declining leprosy expertise is a world-wide phenomenon, but in Nigeria this disturbing trend has been accentuated by several factors. These include the low priority accorded leprosy by government at all levels exemplified by inadequate budget for leprosy, annually. The relatively high daily subsistence allowance paid by the Global Fund to programme officers for programme-related travel inadvertently discourages participation in comparable leprosy activities with significantly lower allowances. Not least, the false interpretation of 'elimination of leprosy' by many a young medical graduate to mean that a career in leprosy holds little future prospects.

Understandably, Nigeria is faced with loss of expertise in the clinical management of leprosy. ${ }^{4}$ In order to counteract the loss of leprosy expertise, Nigeria had initiated a policy of retraining programme staff involved in the management of leprosy cases, but this was never fully implemented. This led to the postulation that to improve the control of leprosy in Nigeria, there is need for orientation of medical and nursing students on leprosy during the period of training. ${ }^{4}$ A study in Uganda on inclusion of leprosy in the curriculum of preservice health training institutions suggested that their National Tuberculosis and Leprosy Control Programme should develop a national plan on leprosy training for students in the health professions. ${ }^{5}$ Another study in Brazil found that medical students who had practical experience with people affected by leprosy were more confident in attending to leprosy 
patients. Furthermore, medical interns in the same study were of the opinion that the practical teaching they received on leprosy during their stay in medical school was not sufficient. ${ }^{6}$

Unfortunately, in Nigeria the medical curriculum accommodates only classroom lectures on leprosy and other skin NTDs without any form of clinical demonstrations. An attempt by the Medical and Dental Council of Nigeria, an arm of government in charge of medical training to introduce clinical demonstrations on leprosy into the medical curriculum in 2009 did not yield the desired results. Anecdotal evidence suggests that the reasons for this failure include inadequate sensitization of medical teachers, as many erroneously opine that leprosy no longer exists in Nigeria and therefore considered it an unnecessary topic, reserved only for the archives. In order to assess the deficiencies regarding leprosy in the present medical training, this study was undertaken to assess knowledge, attitude and treatment practices regarding leprosy among interns and final year medical students.

\section{Methods}

The study design was a cross sectional comparative study of all medical interns and final year medical students in five university teaching hospitals in southeast Nigeria who were willing to participate in the study. A pre-tested, semi-structured questionnaire developed by the researchers was used for the study. The questionnaire was self-administered. Data entry and analysis were done using IBM Statistical Package for Social Sciences statistical software version 22. Frequency tables and cross-tabulations were generated. Chi square test of statistical significance and multivariate analysis using binary logistic regression were used in the analysis and the level of statistical significance was determined by a $p$ value of $<0.05$.

Thirteen variables were used to assess knowledge of leprosy. Each correct answer was assigned a score of one; while an incorrect answer received a score of zero. Respondents with score $\geq 50 \%$ were regarded as having good knowledge. Five variables were used to assess attitude towards leprosy. Each correct answer was assigned a score of one; while an incorrect answer received a score of zero. Respondents with score $\geq 50 \%$ were regarded as having a positive attitude. Good treatment practice of leprosy was determined by attendance to at least one person affected by leprosy during internship or period of medical training. This criterion was used because during medical training, all schools have an equal opportunity to offer leprosy clinical demonstrations to their students since they use the same curriculum for medical education, thereby providing equal opportunity for good practice. However, no student is compelled to participate at any time. From anecdotal evidence, if a student or doctor dares attend to any leprosy patient, he/she must have done so voluntarily with compassion and empathy, considering the high level of stigma existing in the study setting.

Multivariate analysis using binary logistic regression was used to determine the predictors of good knowledge, attitude and treatment practice among the respondents. On each occasion, variables that had a $p$ value of less than 0.2 on bivariate analysis were entered into the logistic regression model to determine the predictors of good knowledge, positive attitude and good treatment practice among the respondents. The result of the logistic regression analysis were reported using adjusted odds ratio and $95 \%$ confidential interval and the level of statistical significance was determined by a $p$ value of $<0.05$.

\section{ETHICAL APPROVAL AND CONSENT TO PARTICIPATE}

Ethical approval for the study was obtained from the Ethics and Research Advisory Board of German Leprosy and TB Relief Association, Nigeria. The respondents were required to sign 
Table 1. Characteristics of the respondents

\begin{tabular}{lcc}
\hline Variable & $\begin{array}{c}\text { Medical interns } \\
(n=477)\end{array}$ & $\begin{array}{c}\text { Medical students } \\
(n=568) \\
N(\%)\end{array}$ \\
\hline Gender & & $N(\%)$ \\
Male & $343(71.9)$ & $352(62.0)$ \\
Female & $134(28.1)$ & $216(38.0)$ \\
Attended clinical demonstration on & & \\
leprosy & & $146(25.7)$ \\
Yes & $117(24.5)$ & $422(74.3)$ \\
No & $360(75.5)$ & \\
\hline
\end{tabular}

to a written informed consent form before questionnaire administration and the nature of the study, its relevance and the level of their participation were made known to them. Respondents were assured that participation in the study was voluntary and all information provided would be kept confidential. Only those who gave consent were considered eligible to participate in the study.

\section{Results}

Of all medical students/interns in the study facilities, a total of 1,045 participated in the study. Overall, a total of 568 final year medical students, representing a response rate of $97.2 \%$ and 477 medical interns representing a response rate of $81.1 \%$, were included in the study.

Table 2 shows the knowledge of leprosy among the respondents. Comparable proportions of medical interns, $88.3 \%$ and medical students were of the opinion that leprosy is curable, $\left(\chi^{2}\right.$ $=0.623, p=0.430)$. Knowledge of three cardinal signs of leprosy was generally poor among medical interns, $(3.8 \%)$ and students $(0.2 \%)$. A higher proportion of the medical students, $29.0 \%$ had good knowledge of leprosy when compared with medical interns, $24.7 \%$ but the difference in proportions was not found to be statistically significant, $\left(\chi^{2}=2.440, p=0.118\right)$. Overall grading of knowledge of leprosy: medical students and interns with good knowledge were $29 \%$ and $24.7 \%$ respectively.

Table 3 shows the attitude towards leprosy among the respondents. A higher proportion of medical interns, $33.8 \%$ were willing to work in a leprosy clinic when compared with the medical students, $24.8 \%$ and the difference in proportions was found to be statistically significant, $\left(\chi^{2}=10.059, p=0.002\right)$. A significantly higher proportion of medical interns, $49.9 \%$ had a positive attitude towards leprosy when compared with the medical students, $38.4 \%,\left(\chi^{2}=13.977, p<0.001\right)$. Overall grading of attitude towards leprosy: medical students and interns with positive attitude were $49.9 \%$ and $38.4 \%$ respectively.

Table 4 shows the treatment practice regarding leprosy among the respondents. A higher proportion of medical interns, $(35.2 \%)$ have attended to someone affected by leprosy during internship or training when compared to medical students, $(17.6 \%)$ and the difference in proportions was found to be statistically significant, $\left(\chi^{2}=42.186, p<0.001\right)$.

Table 5 shows the factors affecting good knowledge of leprosy. The respondents who have attended a clinical demonstration on leprosy were about three times more likely to have good knowledge of leprosy when compared with those who did not. (AOR $=2.9$; 95\% CI: 2.1-3.9.)

Table 6 shows the factors affecting positive attitude to leprosy among the respondents. The respondents who were males were about twice as likely to have positive attitude to leprosy 
Table 2. Knowledge of leprosy among the respondents

\begin{tabular}{|c|c|c|c|c|}
\hline $\begin{array}{l}\text { Variable } \\
\text { (correct answer) }\end{array}$ & $\begin{array}{c}\text { Medical interns } \\
(n=477) \\
N(\%)\end{array}$ & $\begin{array}{l}\text { Medical students } \\
\quad(n=568) \\
N(\%)\end{array}$ & $\chi^{2}$ & $p$ value \\
\hline $\begin{array}{l}\text { Leprosy is still diagnosed in Nigeria } \\
\text { (Yes) }\end{array}$ & 103 (21.6) & $75(13.2)$ & 12.911 & $<0.001$ \\
\hline $\begin{array}{l}\text { Leprosy is curable } \\
\text { (Yes) }\end{array}$ & $421(88.3)$ & $510(89.8)$ & 0.623 & 0.430 \\
\hline $\begin{array}{l}\text { Transmission of leprosy is mainly airborne } \\
\text { (Yes) }\end{array}$ & $228(47.8)$ & $351(61.8)$ & 20.558 & $<0.001$ \\
\hline $\begin{array}{l}\text { Most affected peripheral nerve affected by leprosy } \\
\text { (ulnar) }\end{array}$ & $91(19.1)$ & $102(18.0)$ & 0.216 & 0.642 \\
\hline $\begin{array}{l}\text { Treatment for paucibaccilary leprosy is } 6 \text { months } \\
\text { (Yes) }\end{array}$ & $219(45.9)$ & $230(40.5)$ & 3.107 & 0.078 \\
\hline $\begin{array}{l}\text { Plantar ulcer/ eye damage is WHO Grade } 1 \\
\text { disability } \\
\text { (No) [Grade } 2 \text { is correct answer] }\end{array}$ & $66(13.8)$ & 78 (13.7) & 0.002 & 0.961 \\
\hline $\begin{array}{l}\text { Leprosy reactions are classified into two } \\
(Y e s)\end{array}$ & $266(55.8)$ & $245(43.1)$ & 16.555 & $<0.001$ \\
\hline $\begin{array}{l}\text { No community activities for patients till after } \\
\text { treatment } \\
\text { (No) }\end{array}$ & $173(36.3)$ & $167(29.4)$ & 5.570 & 0.018 \\
\hline $\begin{array}{l}\text { People affected by leprosy suffer stigma in Nigeria } \\
(Y e s)\end{array}$ & $422(88.5)$ & $502(88.4)$ & 0.002 & 0.964 \\
\hline $\begin{array}{l}\text { Knowledge of causative organism for leprosy } \\
\text { (Mycobacterium leprae) }\end{array}$ & 357 (74.8) & $521(91.7)$ & 55.036 & $<0.001$ \\
\hline $\begin{array}{l}\text { Knowledge of } 3 \text { cardinal signs of leprosy } \\
\text { (1. Skin patch with definite loss of sensation. } \\
\text { 2. Enlarged/thickened peripheral nerve with } \\
\text { corresponding loss/impairment of function. } \\
\text { 3. Presence of AFBs in slit-skin-smear) }\end{array}$ & $18(3.8)$ & $1(0.2)$ & 18.797 & $<0.001$ \\
\hline $\begin{array}{l}\text { Laboratory investigation for diagnosis of leprosy } \\
\text { (slit skin smear) } \\
\text { Knowledge of multidrug therapy } \\
\text { (Rifampicin, Clofazimine and Dapsone) }\end{array}$ & $115(24.1)$ & $273(48.1)$ & 11.682 & 0.001 \\
\hline $\begin{array}{l}\text { Knowledge of leprosy } \\
\text { Good } \\
\text { Poor }\end{array}$ & $\begin{array}{l}118(24.7) \\
359(75.3)\end{array}$ & $\begin{array}{l}165(29.0) \\
403(71.0)\end{array}$ & 2.440 & 0.118 \\
\hline
\end{tabular}

when compared with those who were females. (AOR $=1.8 ; 95 \%$ CI: 1.4-2.3.) Similarly, the respondents who had good knowledge of leprosy were about two times more likely to have positive attitude to leprosy when compared with those who had poor knowledge. (AOR = 1.6; 95\% CI: 1.2-2.2.)

Table 7 shows the factors affecting good treatment practice of leprosy. The respondents who have attended a clinical demonstration on leprosy were twice as likely to have good treatment practice concerning leprosy when compared with those who did not. (AOR $=2.1,95 \% \mathrm{CI}$ : 1.5-2.9.) Similarly, the respondents who had good knowledge of leprosy were twice as likely 
Table 3. Attitude towards leprosy among the respondents

\begin{tabular}{|c|c|c|c|c|}
\hline Variable & $\begin{array}{l}\text { Medical interns } \\
\qquad(n=477) \\
N(\%)\end{array}$ & $\begin{array}{l}\text { Medical students } \\
\qquad(n=568) \\
N(\%)\end{array}$ & $\chi^{2}$ & $p$ value \\
\hline $\begin{array}{l}\text { Willing to work in a leprosy clinic } \\
(Y e s)\end{array}$ & $161(33.8)$ & $141(24.8)$ & 10.059 & 0.002 \\
\hline $\begin{array}{l}\text { Support someone cured of leprosy to be a traditional } \\
\text { ruler } \\
(\text { Yes) }\end{array}$ & 355 (74.4) & $426(75.0)$ & 0.046 & 0.831 \\
\hline $\begin{array}{l}\text { Could share public vehicle with one affected by } \\
\text { leprosy } \\
(\text { Yes) }\end{array}$ & $218(45.7)$ & $183(32.2)$ & 19.934 & $<0.001$ \\
\hline $\begin{array}{l}\text { Could share a room with a cured leprosy patient } \\
(Y e s)\end{array}$ & $251(52.6)$ & $257(45.2)$ & 5.644 & 0.018 \\
\hline $\begin{array}{l}\text { Could marry one who was a previous leprosy patient } \\
(Y e s)\end{array}$ & $171(35.8)$ & $167(29.4)$ & 4.925 & 0.026 \\
\hline $\begin{array}{l}\text { Attitude to leprosy } \\
\text { Positive } \\
\text { Negative }\end{array}$ & $\begin{array}{l}238(49.9) \\
239(50.1)\end{array}$ & $\begin{array}{l}218(38.4) \\
350(61.6)\end{array}$ & 13.977 & $<0.001$ \\
\hline
\end{tabular}

Table 4. Treatment practice regarding leprosy among the respondents

\begin{tabular}{lcccc}
\hline Variable & $\begin{array}{c}\text { Medical interns } \\
(n=477) \\
N(\%)\end{array}$ & $\begin{array}{c}\text { Medical students } \\
(n=568) \\
N(\%)\end{array}$ & $\chi^{2}$ & $p$ value \\
\hline Ever attended to one affected by & & & & \\
leprosy during internship or training & $168(35.2)$ & $100(17.6)$ & 42.186 & $<0.001$ \\
$\quad$ Yes & $309(64.8)$ & $468(82.4)$ & & 0.570 \\
$\quad$ No & $(n=168)$ & $(n=100)$ & & 0.323 \\
Number of patients attended to & $105(62.5)$ & $59(59.0)$ & & \\
$\quad$ One patient & $63(37.5)$ & $41(41.0)$ & & \\
$\geq 2$ patients &
\end{tabular}

to have good treatment practice of leprosy when compared with those who had poor knowledge. $(\mathrm{AOR}=1.9,95 \% \mathrm{CI}: 1.4-2.7$.

\section{Discussion}

This study showed a significant association between good knowledge of leprosy and exposure to clinical leprosy demonstrations. Therefore, the role of clinical demonstrations as a crucial component of any leprosy training curriculum aimed at addressing the existing knowledge gaps among future medical professions becomes imperative. Knowledge of the laboratory investigation for leprosy was low among the respondents in this study. It was $10.9 \%$ for medical interns and $18.5 \%$ among medical students. This may be an indication of poor attention to leprosy in the curriculum of medical schools in Nigeria. Slit skin smears (SSS) are usually carried out at Leprosy Referral hospitals and could be an integral part of practical experience during field trips for students and doctors, if included in the curriculum of medical schools 
Table 5. Factors affecting Good knowledge of leprosy among the respondents

\begin{tabular}{|c|c|c|c|c|}
\hline \multirow[t]{2}{*}{ Variable } & \multicolumn{2}{|c|}{ Knowledge of leprosy $(n=1045)$} & \multirow[t]{2}{*}{$p$ value ${ }^{*}$} & \multirow[t]{2}{*}{$\operatorname{AOR}(95 \% \mathrm{CI})^{* *}$} \\
\hline & $\begin{array}{l}\text { Good } \\
N(\%)\end{array}$ & $\begin{array}{c}\text { Poor } \\
N(\%)\end{array}$ & & \\
\hline \multicolumn{5}{|l|}{ Cadre } \\
\hline Medical student & $165(29.0)$ & $403(71.0)$ & 0.118 & $1.2(0.9-1.6)$ \\
\hline Medical intern & $118(24.7)$ & $359(75.3)$ & & 1 \\
\hline \multicolumn{5}{|l|}{ Gender } \\
\hline Male & $177(25.5)$ & $518(74.5)$ & 0.098 & $0.8(0.6-1.1)$ \\
\hline Female & $106(30.3)$ & $244(69.7)$ & & 1 \\
\hline \multicolumn{5}{|c|}{$\begin{array}{l}\text { Attended clinical } \\
\text { demonstration on leprosy }\end{array}$} \\
\hline Yes & 115 (43.7) & $148(56.3)$ & $<0.001$ & $2.9(2.1-3.9)$ \\
\hline No & $168(21.5)$ & $614(78.5)$ & & 1 \\
\hline
\end{tabular}

${ }^{*} p$ value $n$ bivariate analysis. ${ }^{* *}$ Adjusted odds ratio (95\% confidence interval) on multivariate analysis.

Table 6. Factors affecting Positive attitude to leprosy among the respondents

\begin{tabular}{|c|c|c|c|c|}
\hline \multirow[t]{2}{*}{ Variable } & \multicolumn{2}{|c|}{ Attitude concerning leprosy $(n=1045)$} & \multirow[t]{2}{*}{$p$ value ${ }^{*}$} & \multirow[t]{2}{*}{$\operatorname{AOR}(95 \% \mathrm{CI})^{* *}$} \\
\hline & $\begin{array}{c}\text { Positive } \\
N(\%)\end{array}$ & $\begin{array}{c}\text { Negative } \\
N(\%)\end{array}$ & & \\
\hline \multicolumn{5}{|l|}{ Cadre } \\
\hline Medical student & $218(38.4)$ & $350(61.6)$ & $<0.001$ & $0.60 .5-0.9$ \\
\hline Medical intern & $238(49.9)$ & $239(50.1)$ & & 1 \\
\hline \multicolumn{5}{|l|}{ Gender } \\
\hline Male & $336(48.3)$ & $359(51.7)$ & $<0.001$ & $1.81 .4-2.3$ \\
\hline Female & $120(34.3)$ & $230(65.7)$ & & 1 \\
\hline \multicolumn{5}{|c|}{$\begin{array}{l}\text { Attended clinical } \\
\text { demonstration on leprosy }\end{array}$} \\
\hline Yes & $124(47.1)$ & $139(52.9)$ & 0.184 & $1.10 .8-1.5$ \\
\hline No & $332(42.5)$ & $450(57.5)$ & & 1 \\
\hline \multicolumn{5}{|c|}{ Knowledge of leprosy } \\
\hline Good & $146(51.6)$ & $137(48.4)$ & 0.002 & $1.61 .2-2.2$ \\
\hline Poor & $310(40.7)$ & $452(59.3)$ & & 1 \\
\hline
\end{tabular}

${ }^{*} p$ value $n$ bivariate analysis. ${ }^{* *}$ Adjusted odds ratio (95\% confidence interval) on multivariate analysis.

in Nigeria. For example, in India, $30.8 \%$ of physicians that participated in a study knew the diagnostic test for leprosy. ${ }^{7}$ In a study among medical students in the same country, $60.5 \%$ of final year medical students and $54.3 \%$ of first year medical students knew the laboratory test for leprosy. 8

Although leprosy is sometimes included in classroom lectures in Nigeria, most students or their teachers hardly come in contact with persons affected by leprosy, let alone engage in routine clinical demonstrations for leprosy case management. This was why the German Leprosy and TB Relief Association (GLRA) in recent times, began to reach out to some medical schools in southern Nigeria to introduce medical students to essential field experience on leprosy diagnosis and management at Leprosy Referral Hospitals. However, the push has not yet received satisfactory commitment from most medical schools. Indeed, this study observed the need to prioritize clinical demonstration through planned visits to Leprosy 
Table 7. Factors affecting good treatment practice concerning leprosy among the respondents

\begin{tabular}{|c|c|c|c|c|}
\hline \multirow[t]{2}{*}{ Variable } & \multicolumn{2}{|c|}{ Practice concerning leprosy $(n=1045)$} & \multirow[t]{2}{*}{$p$ value } & \multirow[t]{2}{*}{$\operatorname{AOR}(95 \% \mathrm{CI})^{* *}$} \\
\hline & $\begin{array}{c}\text { Good } \\
N(\%)\end{array}$ & $\begin{array}{c}\text { Poor } \\
N(\%)\end{array}$ & & \\
\hline \multicolumn{5}{|l|}{ Cadre } \\
\hline Medical student & $100(17.6)$ & $468(82.4)$ & $<0.001$ & $0.4(0.3-0.5)$ \\
\hline Medical intern & $168(35.2)$ & $309(64.8)$ & & 1 \\
\hline \multicolumn{5}{|l|}{ Gender } \\
\hline Male & $186(26.8)$ & $509(73.2)$ & 0.244 & NA \\
\hline Female & $82(23.4)$ & $268(76.6)$ & & \\
\hline \multicolumn{5}{|c|}{$\begin{array}{l}\text { Attended clinical } \\
\text { demonstration on leprosy }\end{array}$} \\
\hline Yes & $101(38.4)$ & $162(61.6)$ & $<0.001$ & $2.1(1.5-2.9)$ \\
\hline No & $167(21.4)$ & $615(78.6)$ & & 1 \\
\hline \multicolumn{5}{|c|}{ Knowledge of leprosy } \\
\hline Good & $104(36.7)$ & $179(63.3)$ & $<0.001$ & $1.9(1.4-2.7)$ \\
\hline Poor & $164(21.5)$ & $598(78.5)$ & & 1 \\
\hline \multicolumn{5}{|l|}{ Attitude to leprosy } \\
\hline Correct & $144(31.6)$ & $312(68.4)$ & $<0.001$ & $1.5(1.1-2.0)$ \\
\hline Incorrect & $124(21.1)$ & $465(78.9)$ & & 1 \\
\hline
\end{tabular}

Referral Hospitals, since as high as $74.3 \%$ of students and $75.5 \%$ of doctors never attended a clinical demonstration session on leprosy. Worse still, $82.4 \%$ of students and $64.8 \%$ of doctors in this study never had an opportunity to examine or attend to a leprosy patient. Therefore, advocacy visits to policy makers and medical educators for buy-in and possible nationwide scale-up of clinical leprosy demonstration for future medical professionals is strongly recommended. This could be achieved through collaboration with the National TB and Leprosy Control Programme with logistics support from other relevant development partners.

A minor proportion of the respondents, $(24.7 \%$ of medical interns and $29.0 \%$ of medical students) had good knowledge of leprosy. It has been established that lack of knowledge about leprosy exists even among medical practitioners around the world. ${ }^{9}$ This is of concern as it has been found that the success of the leprosy control programme is dependent on the adequate knowledge and practical training on leprosy for healthcare workers. ${ }^{10}$ These proportions that had good knowledge of leprosy in this study are lower than that obtained among medical practitioners in Enugu, Nigeria where $56.3 \%$ of the respondents had good knowledge of leprosy. ${ }^{11}$ However, the study largely focused on general knowledge about leprosy and did not account for relevant practical experience and clinical demonstration of leprosy among the respondents. In a study among medical practitioners in India, $77 \%$ of the respondents had good knowledge of leprosy. ${ }^{12}$ However, in a study among dental students in India, only a minor proportion of the respondents, $10.3 \%$ had good knowledge of leprosy. ${ }^{13}$ Suffice it to say that the results of that study among dental students necessitated the suggestion for targeted educational programmes on leprosy for dental trainees in that country. ${ }^{13}$

A significantly higher proportion of medical interns, 33.8\% were willing to work in a leprosy clinic when compared with the medical students, (24.8\%). A similar result was obtained among medical practitioners in Enugu, Nigeria. ${ }^{11}$ However in a study among medical students in India, 
$95.1 \%$ of final year students and $91.5 \%$ of first year medical students were willing to work in a leprosy referral hospital. ${ }^{8}$ This could mean that there is a huge gap in attitude towards leprosy among medical practitioners in India and Nigeria. This indicates the need for continual orientation of medical students on leprosy during the period of training in Nigeria. Also, a significantly higher proportion of medical interns, $35.8 \%$ would marry someone affected by leprosy when compared with the medical students, $29.4 \%$. These proportions are higher than that obtained in a study among medical practitioners in Enugu, Nigeria. ${ }^{11}$ Similarly, in a study among university students in Mexico, only 30\% of the respondents would consider someone affected by leprosy as a spouse or partner. ${ }^{14}$ Interestingly in a study among medical students in India, $79 \%$ of final year students and $91.5 \%$ of first year students were willing to marry someone affected by leprosy. ${ }^{8}$ This further supports the observation that there is a huge gap in attitude towards leprosy among medical personnel in India and Nigeria.

A higher proportion of medical interns, $49.9 \%$ had a positive attitude towards leprosy when compared with the medical students, $38.4 \%$. These proportions are higher than that obtained among medical practitioners in Enugu, Nigeria ${ }^{11}$ and also among dental students in India. ${ }^{7}$ Since health workers are members of the community in which they normally socialize, it has been postulated that they should acquire health skills and techniques so as to improve their attitudes towards leprosy. ${ }^{15}$ Also since there is a positive relationship between knowledge of leprosy among health workers and their attitudinal predisposition towards people affected by the disease, ${ }^{16}$ there is the need to increase the knowledge of leprosy among the health workers at every available opportunity. A significantly higher proportion of medical interns $35.2 \%$ had good treatment practice of leprosy when compared with the medical students $17.6 \%$. Perhaps the difference in the finding could be attributed to the one year gap between them and the students even though the results signify a low involvement of medical practitioners in the management of cases of leprosy in Nigeria. This is supported by the results of a study among medical practitioners in Enugu, Nigeria which also revealed a poor practice regarding leprosy among the respondents. ${ }^{11}$

From the results of our study, the respondents who attended clinical demonstrations on leprosy were about three times more likely to have good knowledge of leprosy when compared with those who did not attend one. Similarly, the respondents who attended clinical demonstrations on leprosy were twice as likely to have good treatment practice of leprosy when compared with those who did not attend. Surprisingly, comparable proportions of interns and medical students have attended these demonstrations on leprosy. In a study in Enugu, Nigeria, a majority of physicians that participated in the study, $62.5 \%$, had received training on leprosy. That notwithstanding, a higher proportion of the respondents, $92 \%$ were still in need of further training on leprosy. ${ }^{11}$

It has been recognized that the diagnosis of leprosy is confusing even to the experienced leprologists. ${ }^{17}$ Also, lack of knowledge about leprosy exists even among medical practitioners around the world. ${ }^{9}$ This indicates the need for continual training on leprosy for healthcare workers. A study has already identified the need for such training for medical students. ${ }^{18}$ Thus it has been ascertained that knowledge of leprosy among medical students improved after a sensitization programme. ${ }^{19}$ In South Africa, such trainings in leprosy were perceived as a way of being more involved in leprosy service. ${ }^{10}$

The trainings in leprosy have been known to improve both knowledge and attitude towards

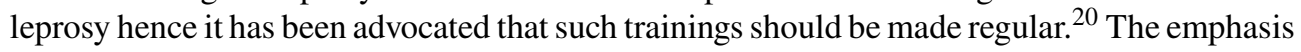
on knowledge of leprosy among caregivers is because it has been identified that knowledge of leprosy determines attitude of the healthcare providers to people affected by the disease. ${ }^{15}$ 
Hence in a study in Assam, India, where knowledge and attitude of healthcare providers were identified as good, there was still a recommendation for such trainings to be regular for health workers so as to reinforce and update their knowledge. ${ }^{21}$ It has been postulated that the prospect of a leprosy free world could only be attained by having primary physicians imbued with adequate knowledge of leprosy hence the need to include more hours of training on leprosy in the medical curriculum ${ }^{8}$ and presently this will be of immense benefit to Nigeria. Undoubtedly, the key to the involvement of medical practitioners in the leprosy control programme is to increase their knowledge of the disease which will positively improve their attitude towards leprosy and treatment practice. Improving the knowledge of leprosy among medical practitioners could be realized by the inclusion of clinical demonstrations on leprosy in the curriculum of medical schools and the subsequent training and re-training of medical practitioners on leprosy and these should be given adequate attention.

\section{LIMITATIONS OF THE STUDY}

Age which could have been useful in determining the predictors of good knowledge and good practice regarding leprosy were not included in the questionnaire. The study however placed emphasis on attendance to clinical demonstrations on leprosy during the period of medical training and immediately after graduation from medical school.

\section{Conclusions}

The study highlighted huge knowledge and attitude deficits on leprosy among young medical professionals in southeast Nigeria. Emphasis should be on improving the knowledge of leprosy among young medics to avoid a dearth of leprosy expertise in future generations. Training plans should consider the need for inclusion of clinical demonstrations on leprosy for medical students during the period of training and also for medical practitioners after graduation from medical school.

\section{References}

1 Nigeria. Neglected Tropical Diseases. Multi-year National Plan. 2015-2020.

2 World Health Organization. Report of fifth meeting of WHO Technical Advisory Group on Elimination of Leprosy. Yangon. 2003.

3 National Tuberculosis and Leprosy Control Programme. Report of Quarterly TB and Leprosy Control Programme Review Meeting 02-04 May, 2019. Federal Ministry of Health, Abuja, Nigeria. 2019.

4 Udo S, Chukwu J, Obasanya J. Leprosy situation in Nigeria. Lepr Rev, 2013; 84: 229-237.

5 Kawuma HJS, Nabukenya-Modupe MG. A study on inclusion of leprosy in the curricula of pre-service health training institutions in Uganda. Lepr Rev, 2011; 82: 296-303.

6 Alves CRP, Araujo MG, Ribeiro MMF, Melo EM. Evaluation of teaching on leprosy at a Brazilian Public Medical School. Revista Brasileira de Educacao Medica, 2016; 40(3): 393-400.

7 Pattanaprichakul P, Chayangsu O, Lerttrujiwanit K, Chairatchaneeboon M, Bunyaratavej S. Assessment of nonDermatologists' knowledge regarding clinical diagnosis of leprosy and practice in slit-skin smear as a basic investigation. Siriraj Med J, 2015; 67: 66-71.

8 Leena R, Priya KS. A study of knowledge and attitude about leprosy among medical students. Indian J Lepr, 2017; 89: 91-97.

9 Meena J, Ankur S. Knowledge and attitude about leprosy among Indian Dental Students in Farida-bad. Clin Diagn Res, 2016; 10(3): ZC48-ZC52.

10 Ukpe IS. A study of health workers' knowledge and practices regarding leprosy care nd control at primary clinics in the Eerstehoek area of Gert Sibande district in Mpumalanga province, South Africa. SA Fam Pract, 2006; 48(5): 16-21.

11 Omotowo BI, Chukwu JN, Ndibuagu EO, Otache EA, Okereke HC. Leprosy and medical practitioners in Enugu, south-east Nigeria. Int J Med Health Dev, 2018; 23(1): 206-211. 
12 Bajaj DR, Matlani BL, Soomro FR, Iqbal MP. Knowledge, attitude and practices regarding leprosy among General Practitioners at Hyderabad. Journal of the College of Physicians and Surgeons Pakistan, 2009; 19(4): 215-218.

13 Jain M, Sharma A, Jain V, Virjee K, Singh S. Knowledge and attitude about leprosy among Indian Dental students in Faridabad. J Clin Diagn Res, 2016; 10(3): 48-52.

14 Graciano-Machuca O, Velare-de la Cruz EE, Ramirez-Duenas MG, Alvarado-Navarro A. University students' knowledge and attitudes towards leprosy. J Infect Dev Ctries, 2013; 7(9): 658-664.

15 Ewhrudjakpor C. Health Care Providers knowledge as correlates of their attitudes towards leprosy sufferers in Nigeria. Ethno-Med, 2008; 2(2): 115-120.

16 Croft RP, Croft RA. Knowledge, attitude and practice regarding leprosy and tuberculosis in Bangladesh. Lepr Rev, 1999; 70(1): 32-42.

17 Kumar B. World Leprosy Day 2015: Renewing commitment for a leprosy free world!. Indian J Med Res, 2015; 141: 1-4.

18 Simi PS, Philip M, Samson JF, Ebenezer S, Nishana K. A study on the basic knowledge, attitude and practices about leprosy among the first year medical and paramedical students of a medical college in South Kerala. Indian Journal of Clinical and Experimental Dermatology, 2018; 4(4): 324-326.

19 Sharma A, Garima G, Sharma N, Sharma S, Singh N, Vohra P, Singh S. Comparative study of knowledge and awareness abot leprosy among medical college students pre and post state leprosy sensitization program in Mewat, Haryana, India. Journal of Clinical and Diagnostic Research, 2018; 12(8): 29-32.

20 Tiwari R, Srivastava DK, Bansal M, Adhikari P, Mishra S. An assessment of the impact of one day training programme on knowledge and attitude of undergraduate students on leprosy at G.R Medical College, Gwalior Madhya Pradesh. Natl J Community Med, 2013; 4(2): 344-348.

21 Kar S, Ahmad S, Pal R. Current knowledge attitudes and practices of Healthcare providers about leprosy in Assam, India. J Glob Infect Dis, 2010; 2(3): 212-215. 